\title{
University Reachout - The Role of Guest Speakers in Communicating with Industry and Other Institutions A Position Paper
}

\author{
S. M. Young, H. M. Edwards, and J. B. Thompson \\ School of Computing and Technology, University of Sunderland \\ St. Peter's Way, Sunderland, SR6 ODD,UK \\ michelle.young@sunderland.ac.uk helen.edwards@sunderland.ac.uk \\ barrie.thompson@sunderland.ac.uk
}

\begin{abstract}
The importance of external inputs into academic environments is highlighted and the actions that have been taken by the School of Computing and Technology at the University of Sunderland to ensure that external speakers are invited from industry and academia to come and give a fresh view on issues related to computing and technology are outlined. Details are then presented on the three series of guest lectures that have been instituted by the School: (i) Distinguished Speaker series, (ii) Practitioner Series, (iii) BCS SocioTech (North) series.
\end{abstract}

\section{Introduction}

Within any educational institution or within any particular academic program there is always the danger of an introverted viewpoint becoming the norm where the academic direction simply follows the particular interests of individual members of staff and each year's content tends to replicate what has been done in the past. It is important for both staff and students that they are exposed to ideas and experiences from outside their own institution and that there are opportunities to hear very different viewpoints - especially from practitioners who can address what is actually happening in the industry. In the School of Computing and Technology at the University of Sunderland we believe that we have been particularly proactive in ensuring that this type of activity occurs and each year we ensure that external speakers are invited from industry and academia to come and give a fresh view on issues related to computing and technology. In the School we currently run three series of lectures that feature guest (external) speakers. These are:

(i) Distinguished Speaker series - where the speakers are academics distinguished in their own field of research,

(ii) Practitioner Series - where the speakers are industry-based and can give an insight into contemporary issues in computing and technology, and

(iii) BCS SocioTech (North) series - a mix of academic/practitioner speakers who focus on the interaction between people, organisations and technology.

Each of the lectures is an open event that can be attended not only by staff and students from our own school but also from other schools in the University, from other universities in the region and also by the public. The events are free, they have a fixed slot in the school timetable (late Wednesday afternoons) and are held in one of the modern lecture theatres at the University's St. Peter's Campus (a campus which has been the recipient of several architectural awards). Students and staff from our own school are actively encouraged to attend the lectures and the events are widely publicised both inside and outside the University. Also, since October 2005, University of Sunderland staff \& students have been 
able to view the archived lectures via WebCT, the University's virtual learning environment. The lecture series is overseen by a small committee of professors from within the School, but possible speakers can be identified by any staff within the School, by external organisations, and by past and current students. The detailed organisation of the series is undertaken by a part-time member of staff who holds a separate contract to do this work. Talks can be classified as being part of more than one series. For example, a speaker from industry and therefore classified as in the Practitioner Seminar Series, depending on the content, may also be classified as in the SocioTech series. The following sections of this paper provide further details of the three series of lectures and illustrate the breadth of topics that are addressed within them. Finally, within an appendix, the publicity material for one of the recent lectures is reproduced to give a feel for what is covered in a typical session.

\section{Distinguished Speaker Lecture Series}

Within the Distinguished Speaker lecture series we have between 4 and 6 speakers during each academic year. Each speaker is an academic of note, distinguished in his/her own field of research. The aim of each talk is to put across some insights from their work in a manner which is accessible to a general computing / technology audience.

So far in the 2005/6 Distinguished Speaker Series, there have been two talks. On the $23^{\text {rd }}$ November, a talk entitled "Design and Development of Learning Objects"was given by Tom Boyle (Professor and Director of the Learning Technology Research Institute (LTRI) at London Metropolitan University). Then on the $7^{\text {th }}$ December, there was "The Odyssey of Information: from Harvey Butterworth to Ziggy Stardust" which was given by Simon Rogerson (Professor and Director of the Centre for Computing and Social Responsibility at De Montfort University, UK) In this talk Professor Rogerson took a fresh look at information

- "the fuel of the modern world".

The 2004/5 series was equally varied in content with the following titles and speakers: "Change in Higher Education" given by Paul Layzell (Professor of Software Management at UMIST, and Vice-President for Communications and External Relations, The University of Manchester), "Mobile Text Input" given by Frode Eika Sandnes (Associate Professor, Oslo University College, Norway), "Discovering Requirements with Scenarios, Innovations and Experiences" given by Neil Maiden (Professor and Head of Human Computer Interaction Design Centre, City University, London), and "Models for Living" given by Mike O'Carroll (Professor Emeritus, University of Sunderland).

The 2003/4 series included the following titles and speakers: "What Role for Artificial Intelligence in the Law?" by John Zeleznikow (Professor of Information Systems, Victoria University, Melbourne), "Information Retrieval and Related Tasks" by Karen Spark-Jones (Professor of Computers and Information at the Computer Laboratory, University of Cambridge), "Views from the Firing Line" given by Leela Damodaran (Professor of Participative Design and Change Management at Loughborough University), and "Death, Drugs, and Dynamite" given by Allan Jamieson (Director of the Forensic Institute, Honorary Fellow in Pathology, University of Edinburgh).

\section{Practitioner Seminar Series}

Within the Practitioner Seminar Series there are between 4 and 6 speakers within each academic year. The speakers are based in industry and give an insight into contemporary issues in computing and technology, and this may be via a conventional presentation, demonstration or workshop activity. 
The Practitioner Seminar Series for the 2005/6 academic year has so far included two talks the first of which was "Design and Development of Learning Objects" by Tom Boyle which has already been mentioned above as it also formed an element within the Distinguished Speaker series. The second talk was "Managing to Avoid Conflict by Conflict Management" given by Simon Wrightson (Associate Director of Gleeds Management Services Limited, UK).

The 2004/5 series included the following titles and speakers: "The Question of Decidability" given by Stephen Brewis (Business Architect for British Telecom), and "The Collaborative Workplace: Fact or Fiction?" given by Brenda Elshaw (Manager: IBM Software Services for Lotus). In the 2003/4 series Allan Jamieson from the Distinguished Speaker series was also classified as a Practitioner Speaker. In the that year's series there was also "IT Evaluation" given by Melanie Clay and "Aspects of Implementing E-government Policies" given by Janice Whyte (Head of e-Government, Sunderland City Council).

\section{SocioTech (North) Lecture Series}

The British Computer Society's SocioTechnical Specialist Group North lecture group hosts talks and events that relate to IT technology and its social impact. This series is affiliated with the SocioTech group at Westminster University, London and organised by Elayne Coakes, (Senior Lecturer in Business Information Management at Westminster Business School). The talks stem from academic research as well as practical industrial viewpoints. The lecture series gives an excellent opportunity to demonstrate the variety of work going on in the field and the issues associated with it. (Details of the activities of the British Computer Society's SocioTechnical Specialist Group can be found via: http://www.sociotechnical.org).

The 2005/6 series include speakers classified in the other two series - Simon Rogerson from the Distinguished Speaker Series and Tom Boyle from the Practitioner Series. This was also the case with the 2004/5 series with Paul Layzell, Neil Maiden, Frode Eika Sandness and Mike O'Carroll being categorised in the Distinguished Speaker Series, and with the 2003/4 series with Paul Layzell, John Zeleznikow, Karen Sparck-Jones, Leela Damodaran and Allan Jamieson being similarly classified.

The 2003/4 SocioTech Series also included speakers from the Distinguished and Practitioner series with Stephen Brewis, Mike O'Carroll, Brenda Elshaw, John Zeleznikow, Janice Whyte and Leela Damodaran. In addition to these, the series included: "Using StructurANTion Theory to Reframe Information Systems, their Research and Practice" given by Christopher Atkinson (Senior Lecturer University of Manchester School of Informatics), "Extreme Programming" given by. Russell Mulcahy (Technical Director, Engica Systems international), "Personalities Within Systems Development Teams" given by Shell Young, (Researcher, University of Sunderland), "Challenges of Integrating Supply Chains for the Built Environment: Exploring The Relevance Of Sociotechnical Design." given by Richard Holti; (Head of Centre for Human Resources and Change Management, Open University Business School, UK), "Better Enterprise Systems Implementation" given by Fan Ipshing (Cranfield University), "E-business" given by Chris Clegg (Professor of Organisational Psychology and Deputy Director of the Institute of Work Psychology at the University of Sheffield), and "Cooperative Inquiry" given by Briony Oates (School of Computing \& Maths, University of Teesside, UK).

The first ever talk in the SocioTech series at Sunderland took place during the 2002/3 academic year, It was entitled "Stakeholders and Boundaries in Strategic Planning Information Systems" and was given by Elayne Coakes (Senior Lecturer in Business 
Information Management at Westminster Business School, Westminster University, UK and organiser of the SocioTech group in London). This was followed by a talk provocatively entitled "Everything you know about Software Engineering is Wrong" given by Keith Braithwaite (Senior Software Developer, Penrillian, UK). The talks during that year also included: Stakeholder Identification and Analysis Technique given by Jean Davison (a Researcher in the PISO unit at the University of Sunderland), "Programming in Bed: Dispersed Software Development" given by Alan Cameron Wills (Consultant in programming methods and a director of Trireme International Ltd, UK), and "The Use of PISO within South Tyneside Trust: Process Improvement for Strategic Objectives (PISO) - a User Perspective" given by Maureen Tan (Head of Performance Management at South Tyneside Health Care Trust).

\title{
Appendix Sample Lecture
}

\section{PRACTITIONER SEMINAR SERIES \& SOCIOTECH LECTURE SERIES}

\author{
Managing To Avoid Conflict By Conflict Management: \\ Achieving project success without resorting to combat \\ SIMON WRIGHTSON \\ Associate Director Of Gleeds Management Services Limited
}

\begin{abstract}
:
A key stone for the success of any project is the management of expectations. When expectations are not managed different parties become entrenched in their views and conflict ensues. This seminar will examine a number of concepts surrounding the avoidance, management and resolution of conflict. The importance of establishing certainty, at the outset of the project, of the project requirements and responsibilities matrix, will be discussed. A project case study will be presented. The consequences of project failure will be discussed, both in respect of business and legal issues. There will be time at the end of the presentation for a discussion of the issues.
\end{abstract}

\section{PROFILE:}

Simon Wrightson is an Associate Director of Gleeds Management Services Limited. Gleeds is a global management and construction consultancy (www.gleeds.co.uk) with offices in 13 countries on 5 continents. Simon is a Senior Practice Expert for Gleeds specialising in Project Management: Planning and Control, Delay and Disruption Analysis and Conflict Management.. He is head of Gleeds Litigation Support / Disputes Consultancy based in Leeds, West Yorkshire. Simon is a qualified production engineer who has worked on major projects in the engineering, construction, information technology and information systems/services sectors. He is a visiting lecturer on the MSc Construction Law and Arbitration Course (Project Management and Conflict Management) at Leeds Metropolitan University. Simon has been appointed as Expert Witness both in Arbitration and Litigation (Technology and Construction Court) giving evidence on Project Delay and Disruption matters. With a legal colleague, Simon is writing a book about Conflict Management. 